\title{
Correlation between Patience and Coping Strategy of Mothers with Autistic Children
}

\author{
Siti Qodariah and Nur Rizky Puspitasari
}

\begin{abstract}
A proper care for autistic children can potentially cause stress for the mothers. The aim of this study is to find out the correlation between the degree of patience and coping strategies of mothers with autistic children in Putraco Indah Elementary School - Bandung. This research is a correlational study. The variables in this study are degrees of patience (Yusuf, et. al, 2012) and coping strategy (Lazarus, 1984). Data were collected through questionnaires and interviews. The statistical analysis techniques is Rank Spearman correlation. The statistical analysis techniques is Rank Spearman correlation. Subjects were mothers because the mother has a very important role in rearingthe children. The results show $r s=0.437$. there is a correlation between patience with coping strategy, the higher level of patience, the more effective coping strategy. The persistent and determine aspect is the highest percentage of patience. From the persistent, sub aspects the discipline is the highest, while thes anticipatory is the highest from the determine.The lowest aspect of patience is resilient, with the lowest percentage is tolerance for frustration. And Coping strategy used by mothers more effectively if use the problem focused coping.
\end{abstract}

Index Terms - Patience, coping strategy, autism.

\section{INTRODUCTION}

Having normal kids are every parent's desire. Parents long for healthy children, both physically and spiritually. However, many children are not born as expected and this leads to various reactions from the parents [1]. These unavoidable and unchanged facts faced by the parents with "different" children causes them to provide extra efforts to raise the children. Compared to raising normal kids, it is a tough task to raise children with special needs ( $\mathrm{CwSN}$ ) as it requires extra energy, thoughts, and higher cost. Some studies show that parents with CwSN suffer from stress in their daily lives. High-level stress can not only seriously affect the parents, but also can cause high-risk illnesses, and even family split. According to [2] parenting stress is not only related to the major life event, but also is being covered with the perceptive of child rearing. Parenting stress is created when there is a gap between the expectation of the parents themselves and children.

Raising autistic children requires not only physically-and-mentally health of the mothers but also the high level patience. Patience (or forbearing) is the state of endurance under difficult circumstances, which can mean persevering in the face of delay or provocation without acting on negative annoyance/anger; or exhibiting forbearance

Manuscript received December 9, 2015; revised March 23, 2016.

The authors are with the Faculty of Psychology, Bandung Islamic University, West Java, Indonesia (e-mail: siti.qodariah@yahoo.co.id, puspitasarizky@gmail.com). when under strain, especially when faced with longer-term difficulties. Patience is the level of endurance one can have before negativity. It is also used to refer to the character trait of being steadfast. So, the mother, who have an autistic children, must have the state of endurance under difficult circumstances to take care their children.

Studies on the patience are rarely, especially with the religion approach, in this case from the point of view of the Islamic religion. Studies that take the concepts based on the Quran and Hadith. This study is a preliminary study about patience. Many aspects or areas of study through the concept of patience, such as clinical psychology, industrial psychology, developmental psychology, and educational psychology. Research on the coping strategy in mothers who have children with autism have been conducted, but research on the relationship between patience with coping strategy is rarely done, especially the use of concepts based on the Quran and Hadith. Therefore, we attempt to correlate the patience with coping strategy in mothers who have children with autism, where it was conducted on a group of mothers who send their children to an inclusive school.

Inclusive schools are required for $\mathrm{CwSN}$ to give them the same chance to have the same learning opportunities as normal kids. This research is done in "Sekolah Dasar/SD" (elementary school) Putraco Indah Bandung, which it has been providing special classes for CwSP since 2003 and today SD PIB has $70 \mathrm{CwSN}$ students and most of them are autistic. The amount of such student raises every year as they are rejected to go to regular schools. At this school they go to the same class with regular students to make them equal in education.

The aim of this study is to determine the relationship between the degrees of patience and coping strategies of the mothers with autistic children as mothers are the ones who have important roles in children's life especially their touch and attachment,. It is a correlation research that is to see the relationship between two or more variables that are quantitative. The variables are degrees of patience and coping strategy.

\section{ReSEARCH Methodology}

This is a correlation survey to examine the relationship between degrees of patience and coping strategy. This study was conducted on mother who have autisric children in Putraco Indah Elementary School - Bandung. , West Java, Indonesia. A correlation research design was employed to evaluate the strength of relation between variables [3]. This study applied a population with the following criteria:

1) were mothers who have an autistic autisric children

2) have another child, besides the autistic child 
3) 1st grade autistic children

4) housewife

Accordingly, the mothers who participated in this study were ten mothers who accompanied her autistic child in Putraco Indah Elementary School - Bandung.

The instruments used by the researcher were patience and coping strategy questionnaire. Patience questionnaire composed based on Yusuf [4] and coping startegy questionnaire composed based on Lazarus [5].

The data collection methods used here are questionnaires while statistical analysis technique for data correlation is Rank Spearman and percentage statistic method (\%) to find out how high frequency of patience and coping strategy are used..

The data collection methods used here are questionnaires and interviews while statistical analysis technique for data correlation is Rank Spearman.

\section{RESULT AND DISCUSSION}

\section{A. Theory}

\section{1) Patience}

Patience with steadfast belief in Allah is one of the best virtues of life in Islam. Through sabr, a Muslim believes that an individual can grow closer to God and thus attain true peace. It is also stressed in Islam, that Allah is with those who are patient, more specifically during calamity and suffering. Several verses in Quran urge Muslims to seek Allah's help when faced with fear and loss, with patient prayers and perseverance for Allah.

The word patience or Shabar comes from the Arabic "Shabara - Shabara - Shabran - Shabara Tun" meaning bear it or withstand anything. That is also the three things : "resist", "altitude something", and "kind stone". From the word "Resist", was born meaning "consistent to survive". The second meaning is born of the word "Shubr", which means trying to reach the top of something. While the third came from the meaning of the word "As-Shubrah" is solid rock or "piece of iron". Thus, what is meant by the word patience is indeed closer to "survive", but held not in the sense of silent, passive, and static but active, innovative, intelligent, and accomplished. This study refers to the word "Kesabaran"/patience defined by Umar Yusuf, et al [4] which divides the patience into three aspects:

a) Firmness is to establishment or the principle (TEGUH)

1) Consequent namely how someone accomplish something with confident, bold and optimistic in accordance with what has been planned.

2) Consistent is how a person behaves consistently, harmony, and according to what has been believed in achieving the target.

3) Discipline is obedient to the rules and orderly in implementing these rules continuously and systematically.

b) Steadfast is a condition when a person is firmed and tough to be on their track to reach their goal (TABAH)

1) Endurance is survival time needed to finish something

2) Struggle to fight in achieving goals

3) Tolerance to frustration: ability to cope the problems that can cause stress in the achievement of the target.

4) Being able to learn from failure: it can strive to always improve the work better.

5) Willing to receive feedback to improve themselves and or their behavior: accepting input from others and make the input as a positive thing that the results achieved for the better.

c) Dilligent is trying continuously until the goal can be achieved (TEKUN)

1) Anticipatory: responsive to something that was / will occur and have a backup plan when facing difficulties in achieving targets / goals.

2) Planned: having plans in achieving goals and realizing these plans.

3) Focused: directing the energy on achieving the goals in the learning processes.

2) Coping strategy

Lazarus \& Folkman [6] defines Coping as a process when a person attemps to the gap between a stressful situation and the ability to meet these.

Lazarus \& Folkman [6] generally distinguish the kinds and functions of Coping in two classifications:

1) Problem Focused Coping (PFC) is a form of coping that focuses on how a person reduces the demands by creative strategic efforts. Individuals tend to use these when they believe that as they believe that the demands are changeable [6]. This strategy involves an attempt to face something threathening [7].

2) Emotion Focused Coping (EFC) is a form of coping that focuses to direct emotional responses againsts a stressful situation. A person can set their emotional responds with behavioral and cognitive approaches.

When a person suffers from alcoholic addiction, seeking emotional support from friends or taking parts in positive activities to escape from the this condition are examples of behavior approaches.

When in such condition a person tries to redefine the situation by comparing his with other people's condition which might worse, it is called cognitive approaches. They believe they can make a few changes to the conditions [6].

\section{3) Utism}

Autism is a developmental disorder characterized by abnormalities in social, language, communication, and behavior aspects and uncommon interest [8]. Autisic person are characterized by secession from social life, lack of social awareness and less attention to others, eye contact avoidance, and specific and repetitive motor activities caused by anxiety and obsessive impulse [8].

The causes of autism are not found yet until today. Some predisposing factors allow the occurrence of autism such as genetic factors, hormonal factors, abnormal prenatal, imperfect birth and certain diseases suffered by the mother during her pregnancy or birth process. These all affect the kid's central nervous system which also can affect brain function. In most autistic children these symptoms can be detected at birth and some of them the symptoms terminate until the age of three. Autistic symptoms of autism appear when at the age of three. Autistic symptoms appear more common to boys compared to girls. The ratio is $3: 1$. 


\section{B. Results and Discussion \\ 1) Result}

Based on statistical calculations using SPSS 17.0 for MS. Windows, the probability value is 0:00. As 00:00<0.05, it indicates that there is a correlation between patience and coping strategy. The Spearman correlation is : 0,437 .

TABLE I: CORRELATION BETWEEN PATIENCE AND COPING STRATEGY

\begin{tabular}{|l|l|l|r|r|}
\hline \multicolumn{5}{|c|}{ Correlations } \\
\hline & & & patience & coping \\
\hline $\begin{array}{l}\text { Spearman's } \\
\text { rho }\end{array}$ & patience & $\begin{array}{l}\text { Correlation } \\
\text { Coefficient }\end{array}$ & 1.000 & .437 \\
\cline { 3 - 5 } & & Sig. (2-tailed) &. & .002 \\
\cline { 3 - 5 } & $\mathrm{N}$ & 10 & 10 \\
\cline { 3 - 5 } & coping & $\begin{array}{l}\text { Correlation } \\
\text { Coefficient }\end{array}$ & .437 & 1.000 \\
\cline { 3 - 5 } & & Sig. (2-tailed) & .002 & \\
\cline { 3 - 5 } & & $\mathrm{N}$ & 10 & 10 \\
\hline
\end{tabular}

The conclusion is that there is a fairly strong correlation between patience and coping strategy (Table I). In the research at SD PIB, at the higher level the patience of the mothers the better the coping strategy.

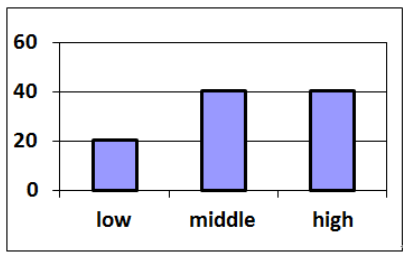

Fig. 1. Patience.

Fig. 1 shows that $20 \%$ of the mothers have the aspect of low patience, $40 \%$ have the aspect of middle patience and $40 \%$ have the high level of patience.

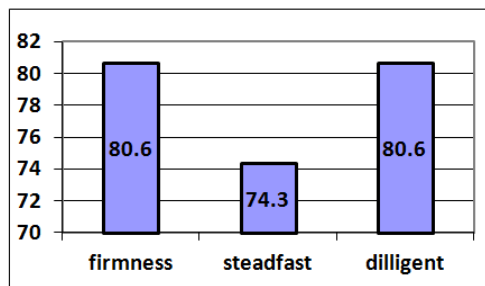

Fig. 2. Patience aspect.

Fig. 2, shows that $80,6 \%$ of mothers are Firmness, 74,3\% are Steadfast, and $80,6 \%$ are Dilligent.

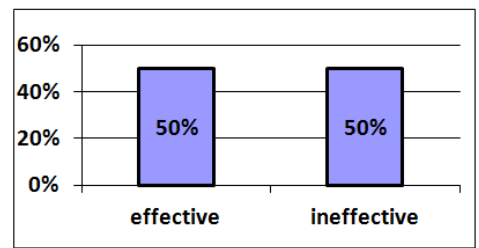

Fig. 3. Coping strategy.

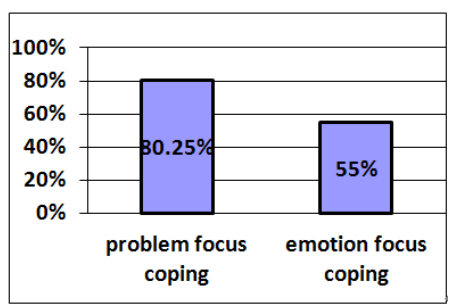

Fig. 4. The ways of coping strategy.
Fig. 3 shows that $50 \%$ of the mothers use effective coping strategy, as well as mothers who used ineffective coping strategy.

Fig. 4 in the coping strategy aspect shows that $80,25 \%$ of the mothers use problem focus coping strategy, and shows that $55 \%$ of mothers use emotion focus coping strategy.

TABLE II: FREQUENCY AND PERCENTAGE FIRMNESS ASPECT

\begin{tabular}{lcccccccc}
\hline Patience & \multicolumn{2}{c}{ Low } & \multicolumn{2}{c}{ Average } & \multicolumn{2}{c}{ High } & \multicolumn{2}{c}{ Total } \\
\cline { 2 - 8 } & F & $\%$ & F & $\%$ & F & $\%$ & F & $\%$ \\
\multirow{2}{*}{ Firm } & 0 & $0 \%$ & 2 & $20 \%$ & 8 & $80 \%$ & 10 & $100 \%$ \\
\hline
\end{tabular}

TABLE III: FREQUENCY AND PERCENTAGE STEADFAST ASPECT

\begin{tabular}{lcccccccc} 
Patience & \multicolumn{2}{c}{ Low } & \multicolumn{2}{c}{ Average } & \multicolumn{2}{l}{ High } & \multicolumn{2}{c}{ Total } \\
\cline { 2 - 9 } & F & $\%$ & F & $\%$ & F & $\%$ & F & $\%$ \\
Steadfast & 0 & $0 \%$ & 4 & $40 \%$ & 6 & $60 \%$ & 10 & $100 \%$
\end{tabular}

TABLE IV: FREQUENCY AND PERCENTAGE DILLIGENT ASPECT

$\begin{array}{lllll}\text { Patience } & \text { Low } & \text { Average } & \text { High } & \text { Total }\end{array}$

Persevering

\begin{tabular}{cccccccc}
\hline $\mathrm{F}$ & $\%$ & $\mathrm{~F}$ & $\%$ & $\mathrm{~F}$ & $\%$ & $\mathrm{~F}$ & $\%$ \\
0 & $0 \%$ & 3 & $30 \%$ & 7 & $70 \%$ & 10 & $100 \%$
\end{tabular}

Based on Table II, III and IV, it appears that $20 \%$ respondents have the aspect of average Firm aspect of patience, $80 \%$ have the aspect of high firm of patience. In the aspect of Steadfast, $40 \%$ of the respondents have the aspect of average steadfast , $60 \%$ have the aspect of high steadfast.. In the aspect of diligent, $30 \%$ has the aspect of average diligent , and $70 \%$ with high diligent.

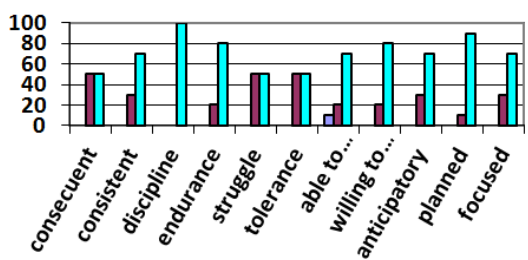

Fig. 5. Frequency and Percentage All Sub aspect of patience.

Based on the Fig. 5, it appears that the sub aspects discipline of the aspect of Firmness has a high percentage of $100 \%$. And sub aspect durability and willing to receive feedback on aspects of Steadfast show the percentage of $80 \%$, while for aspects Diligent, sub aspects of the planned show the highest percentage of $90 \%$.

\section{2) Discussion}

Based on the analysis, there is a fairly strong positive correlation between patience aspect and coping strategy with rs $=0.437$. The higher the patience the more effective coping strategy. Or the lower the patience the less effective coping strategy. The mother who being patient facing autistic children, then she will be able to perform effectively coping with, because patience is restrain the feelings of anxiety, resist feelings of despair and anger, not to complain against any temptation or trouble that happened to her, so that the mother can determine the steps in overcoming the difficulties 
for their child. The results of the study, women who had a firm and persevering nature, showing discipline, and consistent in conducting to overcome difficulties in maintaining their children, mothers also have a plan to overcome the problems with their child, the mother also focus on implementing the steps that have been planned. So, the mother coping is any attempt to regulate environmental demands and conflicts, reducing mismatches between the demands of stressful situations with the mother's ability to meet these demands.

Therefore, it cannot be denied that the mother did problem focused coping more than emotion focused coping, because the problem focused coping is more geared to reduce the demands of stressful situations, that it means coping focused on the problem will deal with the stress of raising children, learning the ways of new skills, tend to use this strategy when they believe that the demands of the situation can be changed [5]. This strategy involves an attempt to do something about the stress conditions that threaten individuals [7]. Problem Focus Coping has been effectively chosen by some mothers for the lives of their autistic children. From the time the children were born they have managed to get ways to overcome the disorder their children suffer from. While the attempt is not as smooth as they have expected, some mothers use Emotion Focus Coping aspect. They just accept and believe the condition of their autistic children as a gift from God.

When viewed from the aspect of patience, overall, $40 \%$ of the mothers with autistic children of SD PIB are high-level patient that is called TEGUH or firmness. TEGUH describes how confident, tough and optimistic the mothers lead their life and reach the goal of life. It is a tough life to live with autistic children. The mothers here in general have always conviced themselves about their children that instead of being autistic, the children have social and academic talent that should be explored.

This study also shows that the mothers are of the low level of TABAH or steadfast. Taking care of autistic children is not easy. Communicating with autistic children can be stressful as they live in their own world are sometimes so that it is difficult to see through. The mothers should find ways to make the children independent in their life which is almost impossible. This leads to the result of TABAH or steadfast is low. They are at high level of TEKUN or dilligent as they manage to explore the children's interest to grow optimally.

\section{CONCLUSION}

Based on the analysis of the data results, it can be concluded :

1) Level of patience and coping strategy have a positive correlation on mother who have autisric children in Putraco Indah Elementary School - Bandung. , West Java, Indonesia

2) The highest level of patience is the aspects of Teguh or firmness and Tekun or dilligent.

3) The sub aspect Discipline is highest level of Teguh or firmness. The sub aspect Anticipative is the highest level of Tekun or dilligent. The lowest level of Patience is Tabah or steadfast. The lowest level sub aspect is Tolerance To Frustration
4) The effective aspect of Coping Strategy more effectively applied by the mothers in the research is Problem Focused Coping

There are some suggestions in this study, there are:

1) TABAH or steadfast is the aspect of patience that need to be improved in which the mother should increase the aspect of "tolerance to frustration" by seeing problems from different point of view or give themselves more time for themselves which is common called "Me Time". Some women use their "Me Time", that is letting themselves free from daily activities by running hobbies or joining communities where they can have "group therapy" by sharing experiences and sharing ideas. "Me Time" can effectively help them to refresh their mind.

2) In taking care autistic children, people with less coping strategies can increase their confidence, control their emotion, get support from family members and community, and are always look for information and consultation with experts and parents who also have autistic children.

\section{REFERENCES}

[1] A. F. Abdullah, Menjadi Ibu Dambaan Umat, Jakarta: Gema Insani, 2002.

[2] C. X. Jiun, W. M. W. Jaafar, and N. M. Ghazali, "The relationship between parenting stress and perceived Children's social problem behavior among Chinese working mothers," International Journal of Social Science and Humanity, vol. 6, no. 3, pp. 157-164, 2016

[3] Sugiyono, StatistikaUntuk Penelitian, Bandung: CV Alfabeta, 2006.

[4] U. Yusuf et. al., Kesabaran, Bandung: Tim Kapita Selekta Psikologi Islami, Unisba, 2012.

[5] R. Lazarus and S. Folkman, Stress, Appraisal, and Coping, New York: Springer Publishing Company, 1984.

[6] E. P. Sarafino, Mental Health: Biopsychosocial Interaction, USA: John Willey and Sons, 2006.

[7] S. E. Taylor, L. A. Peplau, and D. O. Sears, Psikologi Sosial: Edisi 12, Jakarta: Prenada Media Group, 2009.

[8] E. J. Mash and D. A. Wolfe, Abnormal Child Psychology, University of Virginia. Thomson Wadsworth, 2005.

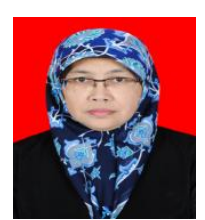

Siti Qodariah is a psychologist. She was born in Bandung, November in 1963. She got her bachelor degree majoring in psychology program in Padjadjaran University, Bandung, Indonesia in 1989. In 2008, she continued her study to pursue her master degree majoring clinical psychology in Bandung Islamic University, Bandung, Indonesia. Finally, she got the degree in 2012. Since 2008, she participated as a speaker in many events and seminars related to her field. Currently, she works as a lecturer in Bandung Islamic University, Bandung. She is also served as a secretary of the master of professional psychology in Bandung Islamic University Postgraduate. Her research mainly focuses on clinical, psychoterapy, crosscultural and islamic psychology Qodariah also joins some institutions, including HIMPSI (Indonesia Association of Psychology), API (Association of Islamic Psychology), IPK (Indonesia Association of Clinical Psychology) and Apsifor (Indonesia Association of Forensic Psychology).

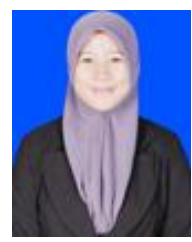

Nur Rizky Puspitasari was born in Bandung in 1992. She is a student of psychology magister at Bandung Islamic University. Puspitasari is a membership in HIMPSI (Indonesia Association of Psychology) 